\title{
Morphometric and Gravimetric Parameters of the Rice Frog Fejervarya limnocharis Living in Areas with Different Agricultural Activity
}

\author{
Panupong Thammachoti ${ }^{1}$, Wichase Khonsue ${ }^{1,2}$, Jirarach Kitana ${ }^{1,2}$, Pakorn Varanusupakul, \\ Noppadon Kitana ${ }^{1,2}$ \\ ${ }^{1}$ Department of Biology, Faculty of Science, Chulalongkorn University, Bangkok, Thailand; ${ }^{2}$ Center of Excellence for Environmental \\ and Hazardous Waste Management (EHWM), Bangkok, Thailand; ${ }^{3}$ Department of Chemistry, Faculty of Science, Chulalongkorn \\ University, Bangkok, Thailand. \\ Email: noppadon.k@chula.ac.th
}

Received July $3^{\text {rd }}$, 2012; revised August $7^{\text {th }}$, 2012; accepted September $10^{\text {th }}$, 2012

\begin{abstract}
Use of agrochemicals in agricultural activity can lead to environmental contamination and affect non-target organisms including amphibians. In northern part of Thailand, there are many areas where agrochemicals, specifically herbicides, have been used for a long time. In this study, the rice frog Fejervarya limnocharis was used as a sentinel species to monitor potential relationship between agricultural activity, in form of herbicide utilization, and altered morphometric and gravimetric parameters. Frogs were field-collected on monthly basis during July 2010-June 2011 from a paddy field with intensive herbicide usage and a reference organic paddy field with no history of herbicide usage. Frogs were subjected to morphometry and gravimetry of liver, kidney, gonad and body. The results showed that condition factor of frogs in the contaminated site were significantly lower than those in the reference site, indicating potential impact on overall health. The gravimetric results showed that liver weight of frogs from the contaminated site were significantly higher than those in the reference site, indicating potential exposure to xenobiotics. There was no significant difference in kidney and testicular weight between these two sites. However, the frog from the impacted site had significantly higher ovarian weight than those from the reference site, indicating potential exposure to estrogenic substance. Overall, the results of this study could be used as early warnings of environmental health problems for other vertebrates living near the agricultural areas including human.
\end{abstract}

Keywords: Herbicide; Amphibian; Sentinel Species; Condition Factor; Hepatosomatic Index; Gonadosomatic Index

\section{Introduction}

Currently, environmental contamination has become one of the global environmental problems occurring in all over the world. The sources of contamination include both industrial and agricultural activities. In agriculture, use of agrochemicals, especially pesticides, is regarded as one of the prominent means of environmental contamination due to the limit capability of agrochemicals to be degraded in nature. When the pesticides are used intensively and continuously for a long time, their residues are likely to be present in the agricultural areas. Nontarget organism living in these areas is thus susceptible to an exposure with the pesticide residues and an adverse effect from this contamination [1].

Pesticide contamination may affect on any vertebrates living in vicinity of the agricultural areas including human. Therefore it is essential to monitor the extent of contamination in physical environment as well as in a representative vertebrate living in the affected area. Also, since non-human vertebrates share several similar structures and function of their organs to those of human, monitoring adverse changes in the animal life could be used as an early warning sign of potential impacts from pesticide contamination to human, making it a sentinel species for environmental health hazards [2].

Amphibians are regarded as one of a suitable sentinel species for environmental contamination. Their natural habitats include agricultural areas where they can be exposed to pesticides [3]. Their existence both in water and on land makes them susceptible to pesticide exposure through several routes, especially through their semipermeable skin [4-6]. Studies on morphology and population of amphibian can thus be used to evaluate the long-term impact of pesticide contamination on vertebrates [7-9]. In addition, since amphibian decline has become a global problem for a few decades and the en- 
vironmental contamination is regarded as the main cause of amphibian decline in agricultural areas [10], study on amphibian response to contamination can also serve as contribution to global amphibian decline problem by elucidating whether the decline is due to chemical contamination, climate change, infection, habitat destruction, or synergistic of these factors [11].

In Thailand, especially Nan Province in the north, there are a lot of agricultural areas where pesticides have been used for a long time. Most of pesticides used in this area include herbicides namely atrazine, glyphosate and paraquat. Atrazine is a known endocrine-disrupting chemicals that can affect on reproductive system of amphibians [12-16] while glyphosate and paraquat are also found to show similar adverse effect on amphibians [17, 18]. Since these herbicides have been intensively used in agricultural areas of Nan Province, the frogs that lived in these areas were unavoidably exposed to the herbicides. Therefore, it is interesting to examine whether utilization of these herbicides will have any impact on the amphibians living in these areas.

In this study, the rice frog Fejervarya limnocharis was used as a sentinel species of environmental health effects from the agricultural activity, in form of herbicide utilization, since stable population of $F$. limnocharis can be found in the agriculture areas making it susceptible to long term exposure and accumulation of xenobiotics [19]. Morphometric and gravimetric parameters of the rice frog living in paddy fields with different degree of herbicide utilization were examined in order to test for influence of herbicide contamination on non-target organisms.

\section{Material and Methods}

\subsection{Study Sites and Field-Sample Collections}

Frogs were field-collected during July 2010-June 2011 from two areas including 1) a contaminated site which is a paddy field with intensive herbicide usage (location: 47Q 068772, UTM 2054283) and 2) a reference site which is an organic paddy field with no history of herbicide utilization (location: 47Q 0686779, UTM 2047187). These two sites are approximately $7.15 \mathrm{~km}$ far from each other. Although several chemicals were used in the contaminated paddy field, previous report indicated that more than 92\% (or approximately 1172.7 tons) of agrochemicals used in agricultural areas at Nan Province was herbicide [20]. The commercially available products of herbicides (atrazine, glyphosate and paraquat) that have been used in the contaminated site ranged from 3.63 to 14.13 L/hectare [20]. Prior study indicated that atrazine residue $(0.15 \mathrm{mg} / \mathrm{L})$ was found in surface water at the contaminated agricultural area, while no herbicide residue was found in the reference area [21]. Male, female and juvenile frogs were collected by hand at night during visual encounter survey [22] on monthly basis. The physical factors including temperature, soil $\mathrm{pH}$, and relative humidity were recorded when the frogs were collected.

\subsection{Morphometric and Gravimetric Analysis}

After transportation to laboratory, frogs were euthanized by immersion into $0.5 \%$ MS-222 solution. Snout-vent length (SVL) and body weight (BW) of each frog was recorded, and weight of liver, kidney, and gonad (ovary or testis) of each frog were measured after dissection. These organs were preserved in $10 \%$ neutral buffer formalin for further study.

Overall health of frog populations was evaluated based on condition factor (CF) [23], an indicator of overall health previously used in this frog species [24]. Briefly, relationship between logarithm of body weight (BW) and logarithm of snout-vent length (SVL) was determined by regression analysis and represented in an Equation (1).

$$
\log \mathrm{BW}=b \operatorname{logSVL}+\log a
$$

Afterward, the condition factor was calculated from the Formula (2).

$$
(\mathrm{BW} \times 100) /\left(a \times \mathrm{SVL}^{b}\right)
$$

In addition to the condition factor, constant $b$ is a scaling coefficient or an indicator of growth pattern of a population.

Gravimetric analysis was used to examine change in status of each organ. Hepatosomatic index (HSI), renosomatic index (RSI), and gonadosomatic index (GSI) as determined from relative weight: (organ weight $\times 100$ / body weight), of liver, kidney, and gonad to the body weight respectively.

\subsection{Statistical Analysis}

All parameters were tested for normal distribution and homogeneity of variance. The condition factors of frog in contaminated site and reference site were compared by non-parametric test (Mann-Whitney rank sum test). Hepatosomatic, renosomatic and gonadosomatic indices were compared between sites by two-way analysis of variance (ANOVA), when site was a major independent factor and season was a second independent factor. In case the significant difference between sites was found, multiple comparison was carried by Student-Newman-Keuls methods.

\section{Results and Discussion}

\subsection{Physical Factors in Study Sites}

The physical factors of the study site including soil $\mathrm{pH}(6.00-7.00)$, temperature $\left(18^{\circ} \mathrm{C}-28^{\circ} \mathrm{C}\right)$, relative 
humidity (73\% - 96\%), were not significantly different between sites. During the field surveys, evidence of herbicide (atrazine, glyphosate and paraquat) utilization in contaminated site was observed by researchers. Therefore, apart from herbicide utilization, physical factors and agricultural activities were similar at these study sites.

\subsection{Condition Factor of the Rice Frogs}

The weight-length relationship of $F$. limnocharis from contaminated and reference sites are shown in Figure 1. The scaling coefficient of frogs in contaminated site (3.2088) is different from those in the reference site (3.0687) indicating different growth pattern between these two populations of frogs living in agricultural areas with different degree of herbicide utilization. This findings agree with several prior reports in which herbicides, especially atrazine, was believed to disturb development and growth pattern of amphibian [14,25-27]. In addition, it was found that the condition factor of frogs in contaminated site $(99.65 \pm 12.26)$ was significantly lower than those in the reference site (102.16 \pm 11.696) (MannWhitney rank sum test, $\mathrm{p}<0.05$ ). The different in condition factor or an indicator of overall health status illustrated that if the body length (SVL) of frogs are equal, frogs from the contaminated site would be lighter or smaller than frogs from the reference site. Since the smaller frogs could be easily captured as a prey in food chain [14], the CF could indicate lower fitness of frogs living in the contaminated area. Since other factors such as climate, geography, agricultural activities and physical factors are similar between these two sites, it seems that utilization of herbicides could affect overall health of the frogs. This is supported by previously published articles

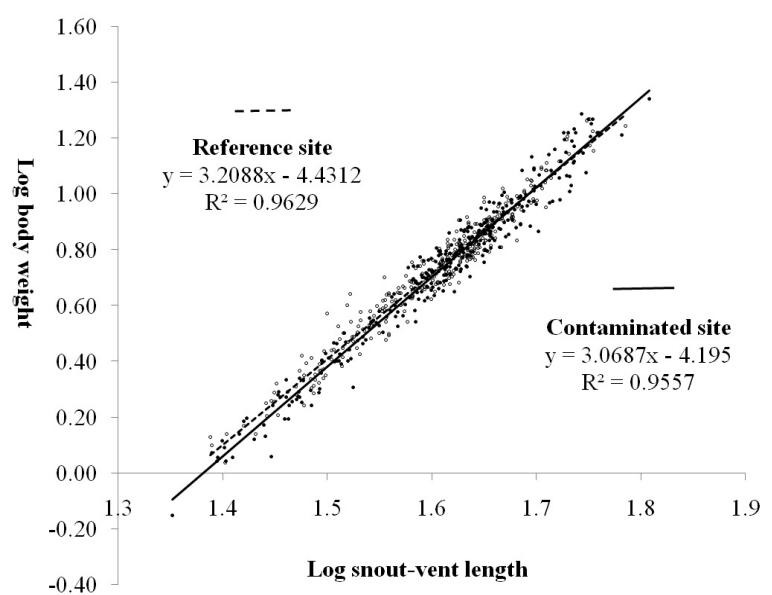

Figure 1. Regression analysis of relationships between body weight and snout-vent length of Fejervarya limnocharis from reference and contaminated sites at Nan Province, Thailand. in which herbicides utilization was found to increase environmental stressors [9], cause toxic effect to the frog [28] or disrupt growth hormone secretion [14].

\subsection{Gravimetric Parameters of the Rice Frogs}

In this study, frogs were groups according to sampling period into 4 groups including late wet period (July 2010), early dry period (October 2010), late dry period (January 2011) and early wet period (April 2011). Gravimetric analysis of frogs by two-way ANOVA showed significant difference between sites as well as between sampling periods in several parameters.

The hepatosomatic indices (HSI) were significantly higher in the contaminated site frogs compared to those in the reference site for both male (Figure 2; overall least

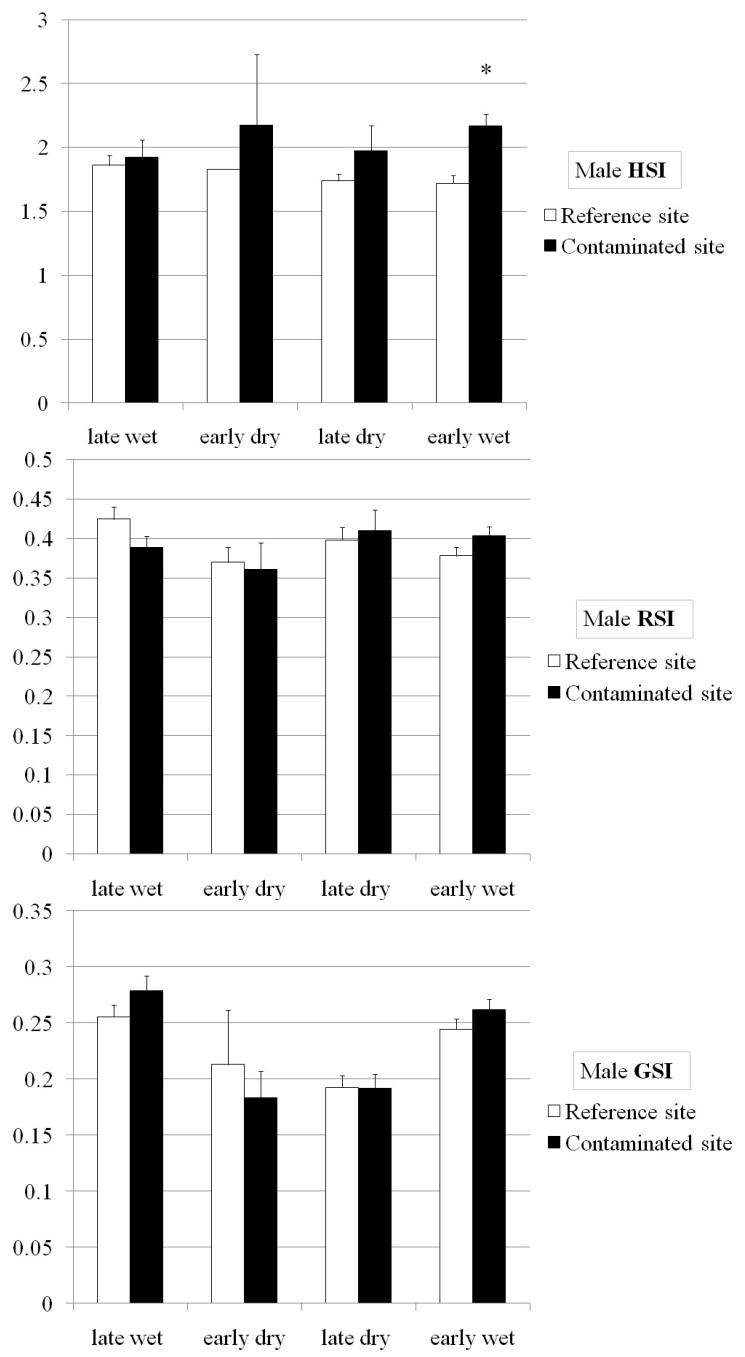

Figure 2. Hepatosomatic, renosomatic and gonadosomatic indices of male frogs from reference and contaminated site at Nan Province, Thailand. Significant site-related difference was found only in hepatosomatic index (two-way ANOVA, $\mathbf{p}<0.05)$. 
square mean: $2.06 \pm 0.09$ vs. $1.79 \pm 0.10 ; \mathrm{p}<0.05)$ and female frogs (Figure 3; overall least square mean: $2.39 \pm$ 0.07 vs. $2.07 \pm 0.07 ; p<0.05)$. Since liver is the main target organ for accumulation and detoxification of xenobiotics [29], it is highly probable that frogs lived in areas with intensive herbicides usage would show enlarge liver as a sign of exposure to and accumulation of xenobiotic contaminants. Evidence of detoxification activity was shown in report by Parvez and Raisuddin [30] that herbicide paraquat can reduce glutathione levels in liver of Channa punctata fish so that the liver have to work harder in order to eliminate this herbicide and other contaminant. The similar finding in the same species of frog was reported by Othman [24] that the rice frogs lived in cadmium contaminated agricultural areas tended to have larger and heavier liver as a result of xenobiotic exposure.

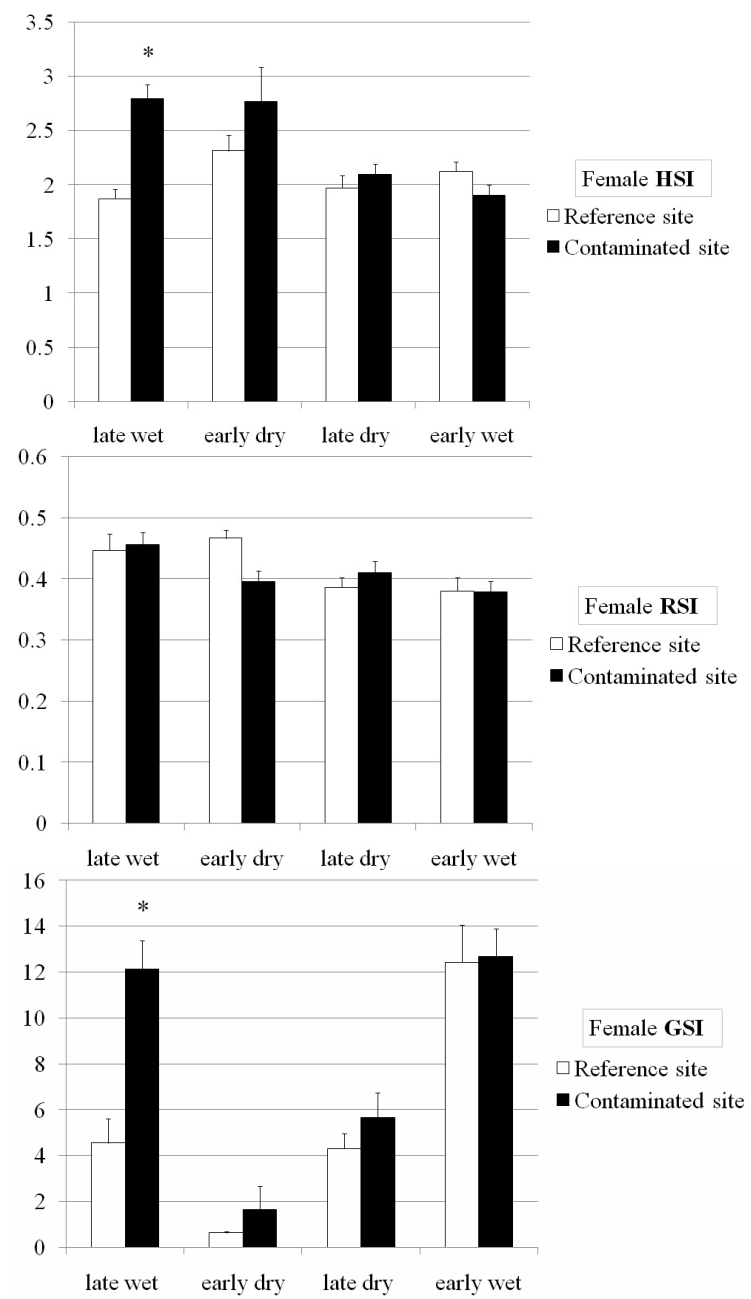

Figure 3. Hepatosomatic, renosomatic and gonadosomatic indices of female frogs from reference and contaminated site at Nan Province, Thailand. Significant site-related difference were found in hepatosomatic and gonadosomatic indices (two-way ANOVA, $\mathrm{p}<0.05$ ).
No significant site-related difference in renosomatic index (RSI) was found in both male (Figure 2; overall least square mean: contaminated site $=0.39 \pm 0.01$, reference site $=0.39 \pm 0.02, \mathrm{p}>0.05$ ) and female frogs (Figure 3; overall least square mean: contaminated site $=$ $0.41 \pm 0.01$, reference site $=0.42 \pm 0.01, p>0.05$ ). It is possible that kidney is not the main target organ for accumulation or detoxification of these herbicides.

No significant site-related difference in the relative testicular weight (Figure 2; overall least square mean: contaminated site $=0.23 \pm 0.01$, reference site $=0.23 \pm$ $0.01, \mathrm{p}>0.05$ ) was found in these frog populations, partly due to high individual variation and small sample size. However, the gonadosomatic index of female frogs (ovarian weight, Figure 3) in contaminated site was significantly higher than those of the reference site frogs (overall least square mean: $8.03 \pm 0.70$ vs. $5.48 \pm 0.68$; $p<$ $0.05)$. The larger ovary in contaminated site frog is possibly due to effects of herbicides on ovarian growth. Herbicide used in agricultural area of Nan Province, especially atrazine, is a known endocrine-disrupting chemicals $[12,31]$ that can exert several estrogenic effects [13$16]$.

Interestingly, most of the previous report on estrogenic effects of atrazine focused on effect on male frog, with few study on female frogs. This study is one of a rare evidence of potential effect of atrazine on reproductive system of female frog. Estrogen is a gatekeeper of female reproductive health [32], therefore contaminant with estrogenic effect should be as effective to some extent. Although female frogs from agricultural areas with intensive herbicide utilization had higher GSI value, the larger and heavier ovary is not always beneficial to animals. In this study, gross anatomy examination revealed that the heavier ovary with mature eggs in the contaminated site frog was found even in dry period when egg laying was not possible since every temporary water bodies was dried up. Therefore, stimulating effect of atrazine herbicide may lead to reduce fecundity fitness of frog living in contaminated site in the future.

Since conflicting results on estrogenic effects of atrazine are also evident in many studies [33-35]. One may argue that reproductive effects of atrazine were still uncertain. However, other herbicides used in this area also showed potential reproductive effects. Paraquat and glyphosate were found to have impacts on reproductive system of Rana esculenta [18]. Glyphosate alone was also toxic to tadpole of Rhinella arenarum [28] and could increase stress in many frog species [17]. Since pesticides are known to cause adverse effect in synergistic fashion [14], mixture of herbicides used in the agricultural areas of Nan Province may also act in similar ways. To further elucidate relationship between herbicide utilization and 
contamination as well as adverse effects to the populated frogs, contaminant analysis for herbicide residues in frog tissue is needed in the future study. In addition, although the rice frog is listed as the least concern species in the IUCN Red List of Threatened Species [36], influence of herbicide should be further examined in regard to potential effects on population of the rice frog as well.

\section{Conclusion}

Although many researches in regard to effects of pesticide on amphibians were available, majority of them was based on laboratory studies [13-15,17-18] with limited information on the actual impact in field environment where synergistic effects of other factors were inevitable [14]. The current study is among a few published researches $[8,37]$ aimed to monitor natural populations of amphibian living in the agricultural area. Overall, the current results suggest that herbicides utilization in agricultural areas could bring about adverse impacts on health status of the populated rice frog. This study could be used as early warnings of environmental health problems for other vertebrates living near the agricultural areas including human.

\section{Acknowledgements}

Financial supports for this work was obtained from the Science for Locale Project under the Chulalongkorn University Centenary Academic Development Plan 20082012, the TRF/BIOTEC Special Program for Biodiversity Research and Training grant BRT T354012, and the 90th Anniversary of Chulalongkorn University Fund (Ratchadaphiseksomphot Endowment Fund). An education grant from the Human Resource Development in Science Project (Science Achievement Scholarship of Thailand, SAST) to PT is fully acknowledged.

\section{REFERENCES}

[1] W. W. Hughes, "Essentials of Environmental Toxicology: The Effects of Environmentally Hazardous Substances on Human Health,” Taylor \& Francis, New York, 1996.

[2] National Research Council, "Animal as Sentinel of Environmental Health Hazard,” National Academy Press, Washington DC, 1991.

[3] M. Z. Khan and F. C. P. Law, "Adverse Effects of Pesticides and Related Chemicals on Enzyme and Hormone Systems of Fish, Amphibians and Reptiles: A Review," Proceedings of the Pakistan Academy of Sciences, Vol. 42, No. 4, 2005, pp. 315-323.

[4] W. E. Duellman and L. Trueb, "Biology of Amphibians," The Johns Hopkins University Press, Baltimore, 1994.

[5] D. Roy, "Amphibians as Environmental Sentinels," Journal of Biosciences, Vol. 27, No. 3, 2002, pp. 187-188.

\section{doi:10.1007/BF02704906}

[6] A. Quaranta, V. Bellantuono, G. Cassano and C. Lippe, "Why Amphibians Are More Sensitive than Mammals to Xenobiotics,” PLoS One, Vol. 4, No. 11, 2009, p. e7699. doi:10.1371/journal.pone.0007699

[7] M. Ouellet, "Amphibian Deformities: Current State of Knowledge,” In: D. W. Sparling, G. Linder and C. A. Bishop, Eds., Ecotoxicology of Amphibians and Reptiles, SETAC Press, Boca Raton, 2000, pp. 617-661.

[8] L. M. Du Preez, et al., "Population Structure of the African Clawed Frog (Xenopus laevis) in Maize-Growing Areas with Atrazine Application versus Non-Maize-Growing Areas in South Africa," African Journal of Herpetology, Vol. 54, No. 1, 2005, pp. 61-68. doi:10.1080/21564574.2005.9635518

[9] F. Soderman, S. Van Dongen, S. Pakkasmaa and J. Merila, "Environmental Stress Increase Skeletal Fluctuating Asymmetry in the Moor Frog Rana arvalis," Oecologia, Vol. 151, No. 4, 2007, pp. 593-604. doi:10.1007/s00442-006-0611-0

[10] D. W. Sparling, G. M. Fellers and L. L. McConnell, "Pesticides and Amphibian Population Declines in California, USA,” Environmental Toxicology and Chemistry, Vol. 20, No. 7, 2001, pp. 1591-1595. doi.org/10.1002/etc.5620200725

[11] W. J. Brige, A. G. Westerman and J. A. Spromberg, “Comparative Toxicology and Risk Assessment of Amphibian,” In: D. W. Sparling, G. Linder and C. A. Bishop, Eds., Ecotoxicology of Amphibians and Reptiles, SETAC Press, Boca Raton, 2000, pp. 727-791.

[12] R. J. Kavlock, "Pesticides as Endocrine-Disrupting Chemicals,” In: R. I. Krieger, Ed., Handbook of Pesticide Toxicology, 2nd Edition, Academic Press, San Diego, 2001, pp. 727-746.

[13] T. B. Hayes, et al., "Hermaphroditic, Demasculinized Frogs after Exposure to the Herbicide Atrazine at Low Ecologically Relevant Doses," Proceedings of the National Academy of Sciences USA, Vol. 99, No. 8, 2002, pp. 54765480. doi:10.1073/pnas.082121499

[14] T. B. Hayes, et al., "Pesticide Mixtures, Endocrine Disruption, and Amphibian Declines: Are We Underestimating the Impact?” Environmental Health Perspectives, Vol. 114, No. 1, 2006, pp. 40-50. doi:10.1289/ehp.8051

[15] T. B. Hayes, et al., “Atrazine Induces Complete Feminization and Chemical Castration in Male African Clawed Frogs (Xenopus laevis)," Proceedings of the National Academy of Sciences USA, Vol. 107, No. 10, 2010, pp. 4612-4617. doi:10.1073/pnas.0909519107

[16] W. Kloas and I. Lutz, "Amphibians as Model to Study Endocrine Disrupters," Journal of Chromatography A, Vol. 1130, No. 1, 2006, pp. 16-27. doi:10.1016/j.chroma.2006.04.001

[17] R. A. Relyea, “The Lethal Impacts of Roundup and Predatory Stress on Six Species of North American Tadpoles," Archives of Environmental Contamination and Toxicology, Vol. 48, No. 3, 2005, pp. 351-357. doi:10.1007/s00244-004-0086-0 
[18] L. Quassinti, E. Macccari, O. Murri and M. Bramucci, "Effects of Paraquat and Glyphosate on Steroidogenesis in Gonads of the Frog Rana esculenta in Vitro," Pesticide Biochemistry and Physiology, Vol. 93, No. 2, 2009, pp. 91-95. doi:10.1016/j.pestbp.2008.11.006

[19] M. S. Othman, et al., "Cadmium Accumulation in Two Populations of Rice Frogs (Fejervarya limnocharis) Naturally Exposed to Different Environmental Cadmium Levels," Bulletin of Environmental Contamination and Toxicology, Vol. 83, No. 5, 2009, pp. 703-707. doi:10.1007/s00128-009-9845-y

[20] P. Chanphong, "The Record of Agrochemicals, Chemical Fertilizer and Organic Fertilizer Utilization at Nan Province in 2008," Nan Provincial Agricultural Extension Office, Nan, 2008.

[21] R. Maneein, W. Khonsue, P. Varanusupakul and N. Kitana, "Association between Atrazine Utilization and Biologic Response of Rice Field Crab Esanthelphusa nani in Paddy Fields of Nan Province, Thailand,” Research Journal of Chemistry and Environment, Vol. 15, No. 2, 2011, pp. 1018-1023.

[22] M. L. Crump and N. J. Scott Jr., "Visual Encounter Surveys,” In: W. R. Heyer, M. A. Donnelly, R. W. McDiarmid, A. C. Hayek and M. S. Foster, Eds., Measuring and Monitoring Biological Diversity, Standard Method for Amphibians, Smithsonian Institution Press, Washington DC, 1994, pp. 84-92.

[23] S. Eastwood and P. Couture, "Seasonal Variations in Condition and Liver Metal Concentrations of Yellow Perch (Perca flavescens) from a Metal-contaminated Environment," Aquatic Toxicology, Vol. 58, No. 1-2, 2002, pp. 43-56. doi:10.1016/S0166-445X(01)00218-1

[24] M. S. Othman, "Using the Rice Frog (Fejervarya limnocharis) as a Sentinel Species for Cadmium Contamination in Tak Province," Ph.D. Dissertation, Chulalongkorn University, Bangkok, 2009.

[25] S. I. Storrs and R. D. Semlitsch, "Variation in Somatic and Ovarian Development: Predicting Susceptibility of Amphibians to Estrogenic Contaminations," General and Comparative Endocrinology, Vol. 156, No. 3, 2008, pp. 524-530. doi:10.1016/j.ygcen.2008.03.001

[26] P. A. Spear, et al., "Study Design, Water Quality, Morphometrics, and Age of the Bullfrog, Rana catesbeiana, in Sub-Watersheds of the Yamasaka River Drainage Basin, Quebec, Canada,” Aquatic Toxicology, Vol. 91, No. 2, 2009, pp. 110-117. doi:10.1016/j.aquatox.2008.09.011

[27] J. R. Lenkowski, G. Sanchez-Bravo and K. A. McLaughlin, "Low Concentrations of Atrazine, Glyphosate, 2,4-Dichlorophenoxyacetic Acid, and Triadimefon Exposures Have Diverse Effects on Xenopus laevis Organ Morphogenesis,” Journal of Environmental Sciences, Vol. 22, No. 9,
2010, pp. 1305-1308.

doi:10.1016/S1001-0742(09)60254-0

[28] R. C. Lajmanovich, A. M. Attademo, P. M. Peltzer, C. M. Junges and M. C. Cabagna, "Toxicity of Four Herbicide Formulations with Glyphosate on Rhinella arenarum (Anura: Bufonidae) Tadpoles: B-Esterases and Glutathione S-transferase Inhibitors," Archives of Environmental Contamination and Toxicology, Vol. 60, No. 4, 2010, pp. 681-689. doi:10.1007/s00244-010-9578-2

[29] G. J. Crawshaw and T. K. Weinkle, "Clinical and Pathological Aspects of the Amphibian Liver," Seminar in Avian and Exotic Pet Medicine, Vol. 9, No. 3, 2000, pp. 165-173. doi:10.1053/ax.2000.7133

[30] S. Parvez and S. Raisuddin, "Effects of Paraquat on the Freshwater Fish Channa punctata (Bloch): Non-Enzymatic Antioxidants as Biomarkers of Exposure," Archives of Environmental Contamination and Toxicology, Vol. 50, No. 3, 2006, pp. 392-397. doi:10.1007/s00244-005-5083-4

[31] R. McKinlay, J. A. Plant, J. N. B. Bell and N. Voulvoulis, "Endocrine Disrupting Pesticides: Implications for Risk Assessment,” Environment International, Vol. 34, No. 2, 2008, pp. 168-183. doi:10.1016/j.envint.20 07.07.013

[32] J. A. McLachlan, E. Simpson and M. Martin, "Endocrine Disrupters and Female Reproductive Health,” Best Practice and Research: Clinical Endocrinology and Metabolism, Vol. 20, No. 1, 2006, pp. 63-75. doi:10.1016/j.beem.2005.09.009

[33] M. B. Murphy, et al., “Atrazine Concentrations, Gonadal Gross Morphology and Histology in Ranid Frogs Collected in Michigan Agricultural Areas,” Aquatic Toxicology, Vol. 76, No. 3-4, 2006, pp. 230-245. doi:10.1016/j.aquatox.2005.09.010

[34] K. K. Coady, et al., "Effects of Atrazine on Metamorphosis, Growth, Laryngeal and Gonadal Development, Aromatase Activity, and Sex Steroid Concentrations in Xenopus laevis," Ecotoxicology and Environmental Safety, Vol. 62, No. 2, 2005, pp. 160-173. doi:10.1016/j.ecoenv.2004.10.010

[35] T. Oka, et al., "Effect of Atrazine on Metamorphosis and Sexual Differentiation in Xenopus laevis," Aquatic Toxicology, Vol. 87, No. 4, 2008, pp. 215-226. doi:10.106/j.aquatox.2008.02.0019

[36] International Union for Conservation of Nature, "The IUCN Red List for Threatened Species,” 2009. http://www.iucnredlist.org/details/58275/0

[37] K. A. McCoy, et al., "Agriculture Alters Gonadal Form and Function in the Toad Bufo marinus," Environmental Health Perspectives, Vol. 116, No. 11, 2008, pp. 15261532. doi:10.1289/ehp. 11536 